\title{
Impact of anxiety, stress and depression related to COVID-19 pandemic on the course of hereditary angioedema with $\mathrm{C} 1$ inhibitor deficiency
}

\author{
Deniz Eyice Karabacak ${ }^{1}$, semra demir², Osman Ozan Yeğit ${ }^{1}$, Ali Can ${ }^{1}$, Kadriye Terzioğlu ${ }^{3}$, \\ Derya Erdoğdu ${ }^{2}$, Muge Olgac ${ }^{4}$, raif $\operatorname{coskun}^{5}$, Bahauddin Çolakoğlu${ }^{1}$, Suna Büyüköztürk ${ }^{2}$, \\ and Aslı Gelincik ${ }^{1}$ \\ ${ }^{1}$ Istanbul University Istanbul Faculty of Medicine \\ ${ }^{2}$ Istanbul University, Istanbul Faculty of Medicine \\ ${ }^{3}$ Kartal Dr Lütfi Kirdar Education and Research Hospital \\ ${ }^{4}$ Şişli Hamidiye Etfal Education and Research Hospital \\ ${ }^{5}$ Prof Dr Cemil Taşçığlu City Hospital
}

December 24, 2020

\begin{abstract}
Background: Hereditary angioedema (HAE) attacks can be provoked with psychological factors. The aim of this study was to assess the effects of anxiety, depression and stress related to COVID-19 pandemic on disease activity of HAE patients during the quarantine period (QP) and the return to normal period (RTNP). Methods: This prospective study was conducted between March 2020 and September 2020 in four allergy centres. Demographic, clinical features and mental health status were evaluated in QP (from March to the beginning of June) and RTNP (from June to the beginning of September) was applied by the government. The 10-point visual analogue scale (VAS10) was used to define the severity of HAE attacks. Depression-AnxietyStress Scale-21 (DASS-21) and Fear of Covid-19 (FC-19) scales were performed to assess mental health status. Results: 139 HAE patients were included in the study. In QP, median attack numbers and median VAS10 scores were 5 (min-max: 0-45) and 6 (min-max: 0-10), respectively. HAE attack numbers, DASS-21 stress, anxiety, depression and total DASS-21 scores, as well as FC-19 scores were higher in QP than RTNP ( $\mathrm{p}=0.001, \mathrm{p}<0,001, \mathrm{p}=0,001, \mathrm{p}<0,001, \mathrm{p}<0.001, \mathrm{p}<0.001$, respectively). However, there was no difference in attack severity scores between the two periods $(\mathrm{p}>0.05)$. Conclusions: This study revealed that the restriction measures during Covid-19 outbreak causes an increase in the number of HAE attacks in relation to anxiety, depression, stress and fear of Covid-19 pandemic. Therefore, it is important to provide psychological support to HAE patients during the pandemic.
\end{abstract}

\section{Hosted file}

Complete manuscript.pdf available at https://authorea.com/users/384981/articles/500479impact-of-anxiety-stress-and-depression-related-to-covid-19-pandemic-on-the-course-ofhereditary-angioedema-with-c1-inhibitor-deficiency 


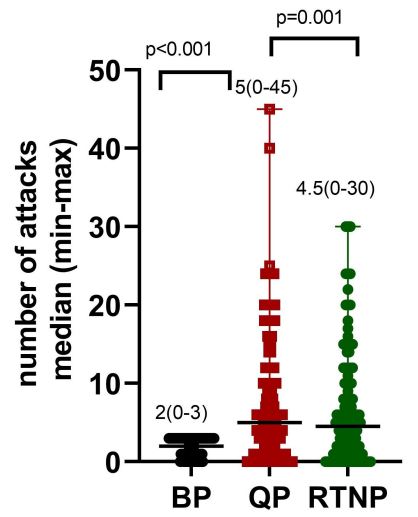

(A)

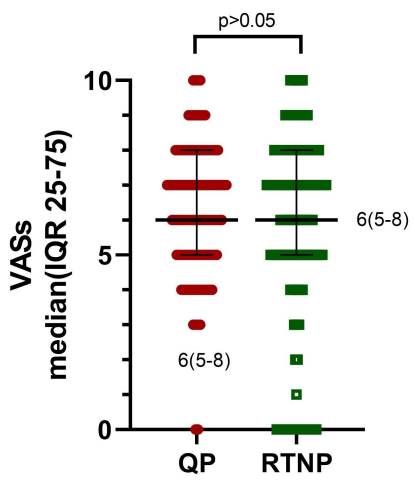

(B)

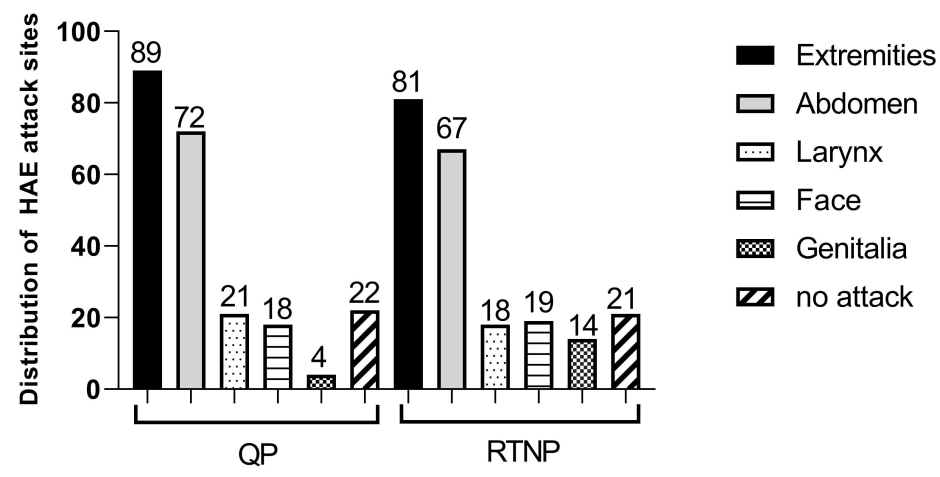




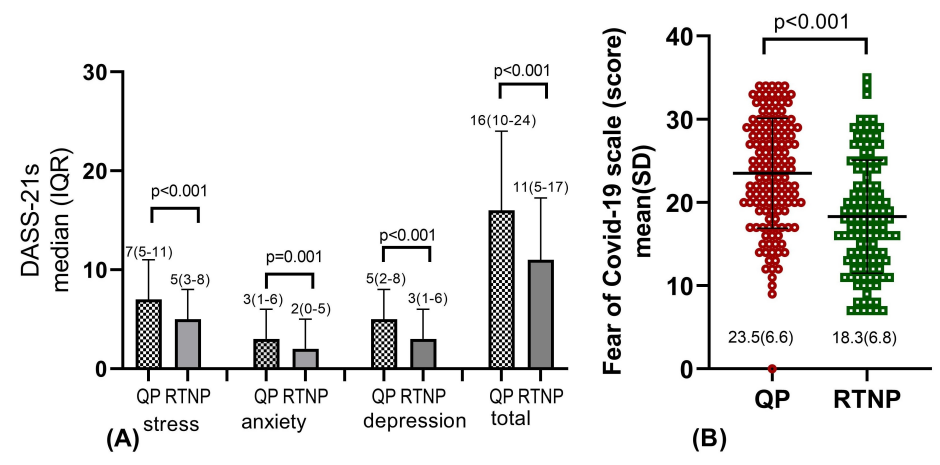

